\title{
Meeting proceedings: Recommendations for improved acute pain services: Canadian collaborative acute pain initiative
}

\author{
David H Goldstein MSC MB BCH BAO FRCPC ${ }^{1}$, Jacqueline Ellis RN PhD², Robert Brown MD FRCP ${ }^{3}$, \\ Rosemary Wilson RN MN ACNP CONC ${ }^{4}$, John Penning MD FRCP ${ }^{5}$, Kenneth Chisom MD FRCP6, \\ Elizabeth VanDenKerkhof $\mathrm{RN} \mathrm{DrPH}^{7}$, and members of the Canadian Collaborative Acute Pain Initiative ${ }^{8}$
}

DH Goldstein, J Ellis, R Brown, et al. Meeting proceedings: Recommendations for improved acute pain services: Canadian collaborative acute pain initiative. Pain Res Manage 2004;9(3):123-130.

The Canadian Collaborative Acute Pain Initiative, established in 2002, is a voluntary, multidisciplinary consortium of acute pain health professionals from across Canada whose goal is to improve acute pain management through discussion and consensus. The group met in January 2002 to define strategic areas related to the treatment of acute pain. The areas identified were: the definition of pain; the epidemiology of pain; the concept of an 'ideal' acute pain management service; education; therapeutic options; symptom management; and research and safety. In November 2002, a second meeting was held to develop objectives and recommendations for the management of acute pain based on the defined areas. The outcome of these discussions is summarized in this paper.

Key Words: Acute pain service; Pain research; Pain team; Patient satisfaction; Quality care; Recommendations
Compte rendu des réunions de l'initiative collective canadienne de soulagement de la douleur aiguë : recommandations visant à améliorer les services

L'initiative collective canadienne de soulagement de la douleur aiguë, mise sur pied en 2002, est un groupe bénévole et pluridisciplinaire de professionnels de la santé provenant de toutes les régions du Canada, voués au soulagement de la douleur aiguë; l'initiative a pour but d'améliorer les services en la matière par la voie des discussions et des consensus. Le groupe s'est réuni en janvier 2002 pour cerner des domaines stratégiques liés au traitement de la douleur aiguë. Il en est ressorti la définition de la douleur, l'épidémiologie de la douleur, le concept du service «idéal » de traitement de la douleur aiguë, la formation, les options thérapeutiques, le traitement des symptômes, la recherche et la sécurité. En novembre 2002, le groupe s'est réuni de nouveau pour élaborer des objectifs et des recommandations en fonction des domaines établis. Voici donc le fruit de ces discussions.

\section{DEFINITION OF PAIN}

The International Association for the Study of Pain defines pain as an unpleasant sensory and emotional experience, which is primarily associated with tissue damage or described in terms of tissue damage, or both (1). Within the context of the present paper, acute pain can be defined as an unpleasant sensory and emotional experience that follows surgically induced tissue injury; as subjective, brief in duration and persistent in nature; as moderate to severe in intensity; and as manifested within the domains of physical, emotional, behavioural and cognitive experiences. The inability to communicate verbally does not negate the possibility that an individual is experiencing pain and needs appropriate pain-relieving treatment (1). For the purpose of this paper the discussion is limited to acute pain in the first $72 \mathrm{~h}$ after the initial insult.

\section{EPIDEMIOLOGY}

Pain remains one of the most common experiences of patients today. In an audit of hospitalized patients $87 \%$ of patients experienced moderate to severe pain (2) (Table 1). Each year, there are approximately five million surgeries performed in Canada (3). Invariably, acute pain and its management is associated with those surgeries. Pain is an important and common health problem in Canada (4). Pain prevalence estimates in the Canadian population range from $11 \%$ to $44 \%(5-10)$. In Ontario alone, pain-related illness costs taxpayers five billion dollars a year. Eighty per cent of all doctor visits have a painrelated component. Pain is one of the significant factors that prolongs hospital stay by up to two to three days (11). Pain adversely affects quality of life and employment status, and is associated with increased use of health care resources (12).

${ }^{1}$ Departments of Anesthesiology and Surgery, Queens University, Kingston General Hospital, Kingston, Ontario; ${ }^{2}$ School of Nursing, University of Ottawa, Ottawa, Ontario; ${ }^{3}$ Department of Anaesthesia, College of Physicians 83 Surgeons of Manitoba, Winnipeg, Manitoba; ${ }^{4}$ Acute Pain Management Services, Queens University, Kingston General Hospital, Kingston, Ontario; ${ }^{5}$ Department of Anaesthesia, Ottawa Hospital Civic Campus, Ottawa, Ontario; ${ }^{6}$ Department of Anaesthesia, Queen Elizabeth II Health Sciences Centre, Victoria General Site, Halifax, Nova Scotia; ${ }^{7}$ Departments of Anesthesiology $\mathbb{E}$ Community Health and Epidemiology, School of Nursing, Queens University, Kingston, Ontario; ${ }^{8}$ Appendix A

Correspondence: Dr David H Goldstein, Departments of Anesthesiology and Surgery, Queens University, 76 Stuart Street, Kingston, Ontario K7L 2V7. Telephone 613-549-6666 ext 3399, fax 613-548-1375, e-mail goldsted@kgh.kari.net 
TABLE 1

Audit of pain in a hospital in the United Kingdom

\begin{tabular}{lcc}
\hline & Patients $(\mathbf{n})$ & $\%$ \\
\hline Pain was present all or most of the time & $1042 / 3162$ & 33 \\
Pain was severe or moderate & $2755 / 3157$ & 87 \\
Pain was worse than expected & $182 / 1051$ & 17 \\
Had to ask for drugs & $1085 / 25,891$ & 42 \\
Drugs did not arrive immediately & $455 / 1085$ & 41 \\
\hline
\end{tabular}

Adapted from reference 2

The epidemiology of pain is not well understood $(4,13)$. The lack of a clear differentiation between acute and chronic pain contributes to the heterogeneity of pain prevalence estimates in the literature. Acute pain that is not adequately managed is thought to sometimes lead to chronic pain (14-16). The incidence of chronic pain after procedures such as thoracotomy may be as high as $50 \%$ (15). Extrapolating from the Canadian Institute for Health Information hospital discharge data on six common surgical procedures and from the incidence and prevalence estimates of chronic postsurgical pain in the literature, estimates of new cases of chronic postsurgical pain have been calculated (Table 2). In 1999 to 2000, over 72,000 new cases of chronic postsurgical pain may have occurred in Canada after surgeries such as hysterectomy, cholecystectomy, hip and knee replacement, breast surgery and thoracotomy (Table 2). If acute postoperative pain has an impact on the development of chronic postsurgical pain, then adequate management of postoperative pain will not only decrease hospital costs through decreased length of stay postoperatively, but will decrease health care spending on the alleviation of chronic pain and suffering through the initial prevention of chronic pain.

\section{Recommendations}

- Generate interest and garner support from national organizations such as the Canadian Collaborative Acute Pain Initiative (CCAPI), the Canadian Pain Society, the Canadian Anesthesiology Society, the Canadian Public Health Association and the Canadian Society for Epidemiology and Biostatistics to facilitate networking and research between researchers interested in pain;

- Reach a consensus on a definition for acute pain;

- Use existing secondary data sources such as the Canadian Institute for Health Information; and

- Facilitate the collection and analysis of perioperative acute pain data.

\section{THE 'IDEAL' ACUTE PAIN MANAGEMENT SERVICE}

The purpose of the Acute Pain Management Service (APMS) is to provide the hospital patient with optimal acute pain management. Optimal acute pain management is defined as a balance between effective analgesic modalities, treatment of side effects and patient safety. There is widespread support for the concept of an APMS (17-19) and the benefits that ensue. Werner et al (20) recently published a review of the effect of an APMS on postoperative outcomes and found that while pain relief per se did not significantly improve postoperative outcome, patient satisfaction was improved and the frequency of pulmonary complications was reduced. Postoperative pain relief programs must be incorporated into a multimodal approach to postoperative outcomes.

The current status of APMS across Canada is largely unknown. A recent survey (21) of Canadian academic centres reported that $89 \%$ of the hospitals responding to the survey had an APMS (42 of 62 hospitals responded). It is unknown how many APMS exist in community hospitals. In order to develop a viable APMS, it must be endorsed and supported by the hospital rather than merely championed by an individual.

The members of CCAPI identified the ideal structure of an APMS. An ideal structure would reflect the process of assessing patients and providing interventions that are known to positively affect pain and suffering. The APMS should incorporate a thorough preoperative or preprocedure patient assessment that focuses on aspects thought to be affected by pain. For example, a thorough documentation of pain and medication use is important to postoperative pain management of patients with chronic pain preoperatively. The anesthesiologist can then take into consideration the specific requirements of the patient when prescribing postoperative pain management.

\section{APMS development guidelines}

The aim of the next section of the paper is to provide a guide to the development of an APMS, including the following elements: planning; implementation; maintenance; long-term follow-up; and evaluation.

Planning: The first component of the planning phase involves the establishment of a multidisciplinary APMS Steering Committee. The Steering Committee is essential to the development of protocols, policies and procedures, and to address administrative issues (22). Gould et al (22) stressed the importance of the presence of clinical experts in patient care areas for mentoring and auditing standards for pain management. Membership in the Steering Committee would include the proposed Medical Director of the APMS, members of nursing administration, a clinical pharmacist, nurse educators and a surgeon. Ad hoc members might also include representatives of biomedical engineering, purchasing, physiotherapy, social work, psychology, information technology and other support services as needed. Input from the department of surgery is essential as they will be major 'consumers' of the services provided by the APMS. In addition, they will need to be comfortable with policies and protocols that limit the types of drugs they can prescribe. For example, it is common practice that when patients are being followed by the APMS no other service prescribes opioids or sedative drugs.

The APMS works to develop best practice pain management throughout the hospital through consensus building across departments and disciplines. Pharmacy and nursing are two services that are key to the success of the APMS, and as such, it is important that they understand the financial implications of developing this service. Pharmacy may be called on more frequently for consultation to the APMS and may be asked to purchase and prepare more analgesic and adjuvant medications. The discipline of nursing provides daily support to the APMS through direct patient care, education and support for the care and monitoring of the patients with acute 
TABLE 2

Estimated incidence or prevalence of chronic postsurgical pain in selected surgical procedures in Canada based on the Canadian Institute for Health Information hospital discharge data and incidence/prevalence estimates from the literature during 1999/2000

\begin{tabular}{lccc}
\hline Procedure & $\begin{array}{c}\text { Number of surgeries performed } \\
\text { in Canada in 1999/2000 (3) }\end{array}$ & $\begin{array}{c}\text { Range of incidence or } \\
\text { prevalence estimate (\%) }\end{array}$ & $\begin{array}{c}\text { Range of estimated incidence or } \\
\text { prevalence of chronic postsurgical pain }\end{array}$ \\
\hline Hysterectomy $(26)$ & 55,404 & $16-50$ & $8865-27,702$ \\
Cholecystectomy $(17,48)^{*}$ & $>50,000$ & $21-27$ & $>10,500->13,500$ \\
Hip replacement $(49,50)$ & 19,853 & $3-35$ & $596-6949$ \\
Knee replacement $(51)$ & 21,649 & $30^{\S}$ & $6495^{\S}$ \\
Breast surgery $(18,52,53)$ & $14,438^{\dagger}$ & $13-49$ & $1877-7219$ \\
Thoracotomy $(19,54)$ & $16,305^{\ddagger}$ & $7-67$ & $1141-10,924$ \\
Total & $>177,649$ & $3-67$ & $29,474->72,789$ \\
\hline
\end{tabular}

${ }^{*}$ Excludes Quebec, Manitoba and Alberta due to differences in how hospital data are reported; †2000/2001 surgical procedure codes 97.12-97.28 (excludes mammoplasty); ${ }^{\ddagger} 2000 / 2001$ surgical procedure codes 46.01-46.5; §Additional data not available

pain. A clinical nurse specialist that has graduate level preparation is in an ideal position to coordinate, monitor and evaluate the services provided by the APMS.

Physiotherapists can also have an impact on postsurgical patients, by reminding patients of the proper use of their pain modalities so they may actively participate in their rehabilitation. Also their feedback to the pain service when patient pain is inadequately controlled and preempting active physiotherapy can make improved care possible. The skills of biomedical engineering are needed to evaluate and maintain equipment used to deliver pain therapies. Information technologists can assist in bringing clinical decision support to the bedside in the form of test results, clinical alerts and access to the literature.

The primary purpose of this multidisciplinary committee is to define needs and to provide guidance for the development of the APMS. A needs assessment should include: a review of the surgical procedures carried out in the institution; a review of the characteristics of the patient population; an assessment of the viability of obtaining input and support from the various stakeholders - anesthesiology, surgery, nursing, pharmacy and administration; a definition of standard pain treatment modalities; and a cost analysis for the proposed service, including the employment of a dedicated APMS nurse(s) (preferably educated at the graduate level with advanced practice qualifications, such as an advanced practice nurse [APN] [23]). The APMS committee is also responsible for selecting assessment tools and defining documentation guidelines and standards for the service. Adoption of the strategy, "Pain as the 5th Vital Sign" has been implemented in some institutions (24). This is an effective screening mechanism for identifying unrelieved pain. Positive pain scores should trigger further assessment, and prompt intervention and evaluation of the pain and its treatment. The inclusion of administration increases the likelihood of obtaining hospital endorsement for the proposed APMS, including the financial commitment necessary to proceed to the implementation phase.

Implementation: Implementation of the APMS is primarily dependent upon the availability of a dedicated APMS APN. While other personnel and services interact and participate in the APMS, the APN provides the continuity necessary to ensure and maintain the service. Staggered implementation of
APMS modalities is necessary to allow for education, monitoring of skills and instilling the confidence necessary to deal with more complex modalities. The recommended sequence is: intravenous patient-controlled analgesia opioids; plexus infusions with local anesthetics; patient-controlled epidural analgesia with opioids; single bolus neuraxial opioids; intermittent, continuous infusions of epidural opioids; and patientcontrolled epidural analgesia or continuous infusion epidurals with local anesthetics with or without opioids. Consideration may be given to restricting complex modalities to certain surgical wards, thereby developing a core group of nurses who are highly skilled in providing care to patients receiving complex pain modalities. APMS facilitators on each ward would provide the support and education for direct care staff and would be a primary source of communication for the APN.

Maintenance: Maintenance of the APMS is dependent on a functional APMS Steering Committee. Communication between bedside nurses should flow primarily through the facilitators and communication from other services should flow through their representative to the committee. Policies and procedures for issues such as recurring side effects, problemsolving algorithms, titration algorithms and weaning should be readily available in both hard copy and on the intranet to allow rapid access to these resources by caregivers.

Anesthesia coverage on the APMS will be dependent on many factors, including hospital size and the availability of personnel (qualified in both anesthesia and advanced practice). Larger tertiary care hospitals may have several staff with subspecialty training in acute pain to provide primary anesthesia coverage; however, most centres will likely rely on only one or two individuals with such training. Smaller centres may have attending anesthesiologists follow their own patients postoperatively. The availability of a dedicated APN allows anesthesiology to work in a consultative capacity.

Follow-up and evaluation: A data collection structure must be implemented to allow for follow-up and evaluation of key outcome measures. Prospective data collection, preferably in electronic format, will result in valuable, timely information for individual patient care, but also for routine audit and evaluation of the outcomes of care. Minimum data capture should include measurement of pain levels, patient satisfaction and incidence of side effects and critical events. 
TABLE 3

Therapeutic options for the management of acute pain based on the identified mechanism of pain

\begin{tabular}{clll}
\hline & Somatic pain & Visceral pain & $\begin{array}{c}\text { Neuropathic } \\
\text { pain }\end{array}$ \\
\hline Appropriate & NSAIDs/COX-2s & NSAIDs/COX-2s & Neural block \\
treatment & Opioids & Opioids & Opioids \\
options & Local anesthesia & Intraspinal local & Tricyclic \\
& Acetaminophen & anesthesia & antidepressants \\
& Cold packs & & Anticonvulsants \\
& Tactile stimulation & & \\
\hline
\end{tabular}

COX-2 Cyclo-oxygenase-2; NSAIDs Nonsteroidal anti-inflammatory drugs

\section{Recommendations}

- Develop the institutional climate that supports an APMS;

- Define the structure and function of an APMS;

- Define the roles of the APMS service providers;

- Develop social marketing strategies to 'sell' the idea of an APMS to senior administration and hospital staff;

- Identify key outcome measures for evaluation of the APMS;

- National dissemination of policies, procedural guidelines, educational materials, pain scales, outcome measures and standardized order sheets related to acute pain assessment and treatment; and

- Develop an acute pain special interest group within the Canadian Pain Society to facilitate practice, education and research in this area.

\section{EDUCATION AND THE APMS}

The content and focus of education will vary depending on a number of factors, including the developmental stage of the institution with respect to best practice pain management. An APMS that is in the planning stages may start by targeting the board of directors, the chief executive officer, the chief of staff and the director of nursing or clinical services. When they understand the aims, objectives and benefits of an APMS, it is advisable to move down the organizational structure and present to the Medical Advisory Committee and senior nursing management. It is essential to include the departments of pharmacy, physiotherapy, respiratory therapy, social work and psychology in the educational sessions about the goals of an APMS because they are stakeholders in the process of developing and maintaining the service. In addition, students from all health care disciplines should be provided with patientfocused, evidenced-based information about best practice pain management and the goals of the APMS. Continued communication with senior administrators and providing them with data that reflect good pain management is a necessary feedback loop for the success of the APMS. Case studies based on actual patients are a powerful way to dramatize the negative impact of unrelieved pain and the positive impact of relieved pain.

The APMS is well positioned to act as the coordinating body for pain education programs targeting both physicians/surgeons (fellows, residents, interns, clerks and medical students) and nurses (APNs, clinical nurses, nurse managers and students). Strategies and content will vary depending on the group and their needs. Clinical rounds focused on pain, case examples that describe best and worst practice in pain management, and the provision of pain workshops are examples of strategies that transmit valuable information and keep people thinking about pain management.

Patient and family education may initially be aimed at helping patients to understand that they have the right to expect good pain management, and that unrelieved pain negatively impacts on their ability to recover from illness, surgery or injury. Many hospitals across Canada and the United States already have well-developed and tested materials that are willingly shared. It is not necessary or cost-effective to reinvent the wheel each time new material is needed.

\section{Recommendations}

- Educate the community on the value of an APMS, its components, role, effectiveness with respect to clinical care and patient satisfaction; and

- Educate administration and health care providers at the undergraduate and postgraduate levels regarding acute pain and its treatment.

\section{THERAPEUTIC OPTIONS}

The goal of this section is to outline the important issues to be considered in delivering effective and safe acute pain therapies to patients. It is not intended to be a comprehensive reference. Major modalities of analgesia and aspects of each modality that are of importance to surgical specialties, such as orthopedic, abdominal, thoracic, vascular, cardiac and urological surgeries can be found online at <www.caj.on.ca $>$.

The most important over-riding principle is the individualization of care to both the patient and the care setting. It is essential to understand that individual factors affect each patient and that pain is an individual experience for each patient. One must be cognizant of additional issues such as acute-on-chronic pain and the operative use of pain and symptom management medications. It should be emphasized that the goals of acute pain management are to obtain an acceptably low pain level that enables the patient to achieve all of the goals necessary for their recovery while at the same time minimizing unwanted side effects from these pain-relieving treatments.

Choices for therapeutic management are based on symptomatology and the mechanism of pain $(25,26)$. Once an assessment has established whether the pain is visceral, somatic or neuropathic, an appropriate treatment algorithm can be applied (Table 3). While these algorithms differ, the commonality they share is that of multimodal therapy. Acute pain interventions should not be limited to the use of systemic analgesic agents, but must also consider the value of procedures such as neuraxial or regional blocks and the addition of adjuvants such as alternative therapies (eg, hypnosis or acupuncture), physical therapy, or in particular for the treatment of neuropathic pain, anticonvulsants $(25,26)$.

Systemic analgesic agents are considered to be the mainstay of therapy for acute pain. Medications frequently considered include opioids, nonsteroidal anti-inflammatory drugs (NSAIDs), both cyclo-oxygenase (COX) nonspecific and COX-2-specific inhibitors, and acetaminophen. Each of these 
categories of medication has its strengths and its limitations as outlined in Table 4. Opioids, for example, are effective against moderate to severe pain of various etiologies. Morphine is perhaps the best-known opioid, as are fentanyl and hydromorphone. For more mild to moderate pain, NSAIDs and acetaminophen can be effective and allow for an opioid-sparing effect. NSAIDs inhibit COX, which in turn inhibits prostaglandin synthesis, thereby producing an anti-inflammatory effect. The COX-2 inhibitors, such as celecoxib, rofecoxib and the recently introduced valdecoxib, specifically inhibit COX-2 to reduce inflammation (27). Type $1 \mathrm{COX}$ is thus preserved and the gastrointestinal adverse events frequently associated with other NSAIDs are more limited (28). A desirable quality of the COX-2 inhibitors in the perioperative period is the lack of platelet inhibition (29).

\section{Pain management for specific surgeries}

Orthopedic surgery: Issues that are specific to the management of acute pain associated with orthopedic surgery centre around the use of NSAIDs and COX-2 inhibitors because of their effects on prostaglandin formation. NSAIDs clearly inhibit bone healing, and there is significant controversy regarding the potential for $\mathrm{COX}-2$ inhibitors to do the same. Animal data (30) suggest that COX-2 inhibitors are subject to the same limitation, while the only human study to date shows no difference, but is retrospective (31). In addition to the use of systemic pharmaceutical agents, multimodal therapy for orthopedic surgical management could include regional analgesia and rehabilitation to improve range of motion.

Abdominal surgery: Epidural analgesia is a very effective method of managing postoperative pain associated with abdominal surgery. Patients receiving epidural analgesia experience several advantages: they are more alert, experience fewer side effects, enjoy better pulmonary function, are usually extubated earlier and spend less time on a ventilator, which offers a cost-saving potential. Studies suggest that postoperative epidural analgesia is also associated with reduced postoperative mortality and morbidity in high-risk patients (32) and epidural infusions of local anesthetics significantly reduce the risk of leg deep vein thrombosis after surgery (33). Administration of epidural anesthesia has been associated with more rapid recovery of gastrointestinal motility than parenteral or epidural opioids. Therefore, epidural anesthesia with local anesthetics appears to be a preferable way to minimize adverse events following abdominal surgery (34).

Thoracic surgery: The most severe form of postsurgery pain is often considered to be post-thoracotomy pain. Thoracotomy can markedly reduce postoperative pulmonary function and the choice of pain management has major implications (35). Because of the limitations of single modalities, a variety of agents and techniques have been explored, including the use of systemic opioids, NSAIDs and ketamine, regional analgesia (including epidural, spinal, paravertebral, intercostal and intrapleural techniques) and cryoanalgesia. Thoracic epidural analgesia using a combination of different local anesthetic agents and opioids has a well-proven track record of efficacy. Moreover, there is evidence that thoracic epidural local anesthetic reduces pulmonary morbidity.

Vascular surgery: Vascular patients typically have a high risk of comorbid disease, including ischemic heart disease and chronic lung disease as well as diabetes mellitus and renal disease. Therefore, they are typically higher risk patients. In
TABLE 4

Strengths and limitations of currently available agents commonly used to treat acute pain

\begin{tabular}{lll}
\hline & Strengths & Limitations \\
\hline Opioids & Efficacious & Gl effects \\
& $\begin{array}{l}\text { Versatile } \\
\text { Widely available } \\
\text { Relatively inexpensive }\end{array}$ & $\begin{array}{l}\text { Central nervous system } \\
\text { effects, depression }\end{array}$ \\
& Itch \\
& Opioid-sparing & Sedation \\
NSAIDs & Gl effect, especially \\
& Possibly reduce opioid & persons $>65$ years of age \\
& side effects & Platelet inhibition \\
& & Asthma \\
Acetaminophen & No Gl effects & No anti-inflammatory effect \\
& No renal platelet effects & Hepatotoxicity \\
COX-2 & Reduced GI effects & Renal/asthma issues - \\
inhibitors & Similar efficacy to NSAIDs & as for NSAIDs \\
& Platelet-sparing & Possible increase in ischemic \\
& & events versus NSAIDs
\end{tabular}

COX-2 Cyclo-oxygenase-2; GI Gastrointestinal; NSAIDs Nonsteroidal antiinflammatory drugs

addition, they may already be on anticoagulant therapy and these patients typically receive anticoagulant therapy intraoperatively or postoperatively.

Major vascular procedures are appropriate for intravenous patient-controlled analgesia or epidural analgesia. One major complication with major vascular surgery is postoperative renal dysfunction, and it may be prudent to rule this out before administering NSAIDs or COX-2 inhibitors in a multimodal analgesic acute pain treatment plan. A special caveat to mention is the possibility of the precipitation of ischemic events. Animal and human coagulation studies have shown an increase in platelet function due to selective prostacycline inhibition (29).

There have not yet been sufficient human data to refute this concern, and it must therefore be acknowledged until there is proof of no risk. There is also the potential for reduction in graft thrombosis with neuraxial local anesthetic techniques in lower limb procedures.

A number of studies (36-38) have demonstrated that preoperative epidural analgesia results in a decreased incidence of patients developing persistent phantom limb pain postamputation when treated preoperatively with epidural analgesia. There is some evidence that patients receiving local anesthetic through a peripheral nerve sheath postoperatively may not develop persistent limb pain (39). Consideration of an intraoperative neuraxial technique or placement of a nerve sheath catheter for delivery of postoperative local anesthetic should be considered in this patient population.

Cardiac surgery: In general, cardiac patients are older patients with associated comorbid diseases. They often receive systemic doses of heparin during their operative procedures. Pain is present in multiple sites in many cardiac patients; such sites often include the sternum, chest tube sites and saphenous vein harvesting sites.

In cardiac surgery, one of the major limitations with neuraxial analgesic techniques is the administration of systemic doses of heparin and the potential subsequent risk of neurological injury related to these techniques. The potential for these 
patients to develop coagulopathy is another factor that could influence the choice of neuraxial techniques. There is no convincing evidence that neuraxial analgesic techniques provide any significant benefit to patient outcome.

Parenteral opiate administration has been used for postoperative analgesia in the cardiac surgery population. The advantages are familiarity with the techniques by staff and coverage of wide areas of pain-producing stimuli by the drug delivered parenterally. Disadvantages include all of the usual side effects of opioid drugs, including sedation, confusion, respiratory depression, nausea, vomiting, pruritis, constipation and urinary retention.

Urological surgery: Urological patients are like the vascular patients in that they are older and may experience multisystem disease. The common procedures are transurethral resection of the prostate, nephrectomy and ileal conduit patients. The pain of a patient who underwent transurethral resection of the prostate may be treated with oral NSAIDS, acetaminophen or a small dose of intrathecal morphine. For open urological procedures, epidurals improve analgesia and gut function. Following a nephrectomy or ileal conduit surgery, the patient is best served if there are no contraindications with epidural local anesthetics and opioids in addition to NSAIDs, if appropriate. This is not to say that a patient-controlled analgesia is not appropriate.

\section{Recommendations}

- Identify pain-related issues in the preoperative setting and take them into account when planning a pain management strategy for the postoperative period;

- Identify the possible therapeutic measures available for treatment of perioperative pain;

- Define care maps with specific acute pain management strategies for specific cases using multimodal therapy (NSAIDs, local anesthetics, opioids and N-methyl-Daspartate inhibitors);

- Regularly assess these maps regarding their effectiveness and update them with the latest evidence; and

- Create a link with the epidemiologists to evaluate such tools.

\section{SYMPTOM MANAGEMENT}

Analgesic side effects can be more distressing for patients, families and health care professionals than the pain itself (40). Nausea, vomiting, sedation and pruritis (41) are the most common side effects of therapy. Antihistamines, anticholinergics, antimuscarinics, dopaminergic blockers, serotonin antagonists and steroids are commonly prescribed in the treatment of side effects. Patients at risk for severe postoperative nausea and vomiting secondary to anesthetic or analgesic drugs should be identified and a strategy put in place to prevent or reduce chances of nausea and vomiting (42), including avoidance of emetogenic agents intraoperatively and the use of prophylactic antiemetics. Opioid agonist antagonists (eg, nalbuphine) or opioid antagonists (eg, naloxone) should be kept immediately available and can be used in the treatment of side effects. The availability of preprinted order sheets is a simple strategy to enhance the treatment of side effects.

\section{Recommendations}

- Efforts are necessary to develop pain modalities that minimize side effects;

- Pain strategies must include treatment of side effects of therapy; and

- The effectiveness of side effect therapy should receive constant evaluation.

\section{RESEARCH AND SAFETY}

Acute pain and symptom management should be evidence based, involve multimodal therapy, and be provided by a multidisciplinary team that incorporates continuous quality improvement into all aspects of care. This can only be achieved when research becomes part of the acute pain strategy, and is not only driven by best practice research but contributes to best practice research. This strategy can be achieved with cooperation between all stakeholders. At the basic science level, new receptor studies are needed to develop novel pain therapies with minimal side effects. At the clinical level, scientists must identify a core data set, including a data dictionary (25) to provide support for an electronic patient assessment database that can evolve with feedback on modality effectiveness, side effect prevalence and treatment (43-45), as well as patient safety issues $(46,47)$. Epidemiological studies would provide insight into the impact of pain on the population, including health care utilization, quality of life and impact on work. This data rich resource will contribute to the quest for excellence in the management of pain in both the hospital and the community setting by creating an ongoing prospective database that would contribute valuable information for clinical, administrative and research initiatives $(44,45)$.

\section{Recommendations}

- Ongoing clinical patient assessments recorded (surveillance) to contribute to an acute pain research strategy;

- Creation of a minimum dataset;

- Collaboration between centres on the recording of patient assessments;

- Support for the collection, analysis and reporting of assessment data; and

- Establishment of a centre for research in acute pain comprised of the assessment-contributing centres.

\section{CONCLUSION}

Collaboration between stakeholders can result in Canada strengthening its position as a global leader in pain and symptom management. Dedication to improvement and an aspiration for excellence will be realized with constant evaluation of clinical and research activity in acute pain care. The members of CCAPI are committed to the concepts outlined in this document.

ACKNOWLEDGEMENTS: We wish to thank Karma Inc and Fusion MD Medical Science Network for logistic support and editorial contributions.

FUNDING: Supported by an educational grant from Pfizer Canada/ Pharmacia Canada. 


\section{APPENDIX A}

Members of the Canadian Collaborative Acute Pain Initiative: Juan Francisco Asenjo, Neal Badner, David Boyd, Krista Brecht, Norman Buckley, Catherine Cahill, Cindy Carnegie, Sarah Connelly, Étienne de Médicis, Thresa Dunn, G Allen Finley, Heather Fisher, Murray Hong, Kim Horill, Chander Kamra, Debbie Lacheur, Phyllis Jeanne Lamb, Peter MacDougall, Carolyne-Jane Montgomery, Shirley Musclow, Vinod Nair, Lori Palozzi, James Paul, Brenda Poulton, Edwin Redmond, Sara Robinson, Monakshi Sawhney, Jennifer Stinson, Ian R Sutton, Richard Tilsworth, Dean Tripp, Paul S Tumber and Jim Watson.

\section{REFERENCES}

1. IASP Task Force on Taxonomy. Classification of Chronic Pain, 2nd edn. Seattle: IASP Press; 1994.

2. Bruster S, Jarman B, Bosanquet N, Weston D, Erens R, Delbanco TL. National survey of hospital patients. BMJ 1994;309:1542-6.

3. Canadian Institute for Health Information. Health Care in Canada. 2002.

4. Van Den Kerkhof EG, Hopman WM, Towheed TE, Anastassiades TP, Goldstein DH, Canadian Multicentre Osteoporosis Study Research Group. The impact of sampling and measurement on the prevalence of self-reported pain in Canada. Pain Res Manag 2003;8:157-63.

5. Millar WJ. Chronic pain. Health Rep. 1996;7:47-53.

6. Elliott AM, Smith BH, Penny KI, Smith WC, Chambers WA. The epidemiology of chronic pain in the community. Lancet 1999;354:1248-52.

7. Elliott AM, Smith BH, Smith WC, Chambers WA. Changes in chronic pain severity over time: The Chronic Pain Grade as a valid measure. Pain 2000;88:303-8.

8. Birse TM, Lander J. Prevalence of chronic pain. Can J Pub Health Revue Canadienne de Sante Publique. 1998;89:129-31.

9. Moulin DE, Clark AJ, Speechley M, Morley-Forster PK. Chronic pain in Canada - Prevalence, treatment, impact and the role of opioid analgesia. Pain Res Manag 2002;7:179-84.

10. Crook J, Rideout E, Browne G. The prevalence of pain complaints in a general population. Pain 1984;18:299-314.

11. Miaskowski C, Crews J, Ready LB, Paul SM, Ginsberg B. Anesthesia-based pain services improve the quality of postoperative pain management. Pain 1999;80:23-9.

12. Smith BH, Elliott AM, Chambers WA, Smith WC, Hannaford PC, Penny K. The impact of chronic pain in the community. Fam Pract 2001;18:292-9.

13. Macrae WA, Davies HT. Chronic postsurgical pain. In: Crombie IK, Croft PR, Linton SJ, SeResche L, Von Korff M, eds. Epidemiology of Pain. Seattle: IASP Press, 1999:125-42.

14. Coderre TJ, Katz J. Peripheral and central hyperexcitability: Differential signs and symptoms in persistent pain. Behav Brain Sci 1997;20:404-19.

15 Katz J, Jackson M, Kavanagh BP, Sandler AN. Acute pain after thoracic surgery predicts long-term post-thoracotomy pain. Clin J Pain 1996;12:50-5.

16. Coderre TJ, Katz J, Vaccarino AL, Melzack R. Contribution of central neuroplasticity to pathological pain: Review of clinical and experimental evidence. Pain 1993;52:259-85.

17. Ros E, Zambon D. Postcholecystectomy symptoms. A prospective study of gall stone patients before and two years after surgery. Gut $1987 ; 28: 1500-4$.

18 Tasmuth T, von Smitten K, Hietanen P, Kataja M, Kalso E. Pain and other symptoms after different treatment modalities of breast cancer. Ann Oncol 1995;6:453-9.

19. Roxburgh JC, Markland CG, Ross BA, Kerr WF. Role of cryoanalgesia in the control of pain after thoracotomy. Thorax 1987;42:292-5.

20. Werner MU, Soholm L, Rotboll-Nielsen P, Kehlet H. Does an acute pain service improve postoperative outcome? Anesth Analg 2002;95:1361-72.

21. Goldstein DH, VanDenKerkhof EG, Blaine WC. Acute pain management services have progressed, albeit insufficiently in Canadian academic hospitals. Can J Anaesth 2004;15:231-5.

22. Gould TH, Crosby DL, Harmer M, et al. Policy for controlling pain after surgery: Effect of sequential changes in management. BMJ 1992;305:1187-93.
23. Musclow SL, Sawhney M, Watt-Watson J. The emerging role of advanced nursing practice in acute pain management throughout Canada. Clin Nurse Spec 2002;16:63-7.

24. Ohio State Medical Association - Pain: The Fifth Vital Sign One year later <http://www.osma.org/pub/om/om-0200-art3.cfm> (Version current at August 9, 2004).

25. American Patient Safety Foundation. Data Dictionary Task Force. Anesthesia patient safety foundation and leading anesthesia information systems manufacturers launch coordinated effort to improve patient safety. <www.gasnet.org/societies/apsf/ddtf/launch.php $>$ \{Version current at July 29, 2004).

26. Farquhar CM, Sadler L, Harvey S, McDougall J, Yazdi G, Meuli K. A prospective study of the short-term outcomes of hysterectomy with and without oophorectomy. Aust N Z J Obstet Gynaecol 2002;42:197-204.

27. Gilron I, Milne B, Hong M. Cyclooxygenase-2 inhibitors in postoperative pain management: Current evidence and future directions. Anesthesiology 2003;99:1198-208.

28. FitzGerald GA, Patrono C. The coxibs, selective inhibitors of cyclooxygenase-2. N Engl J Med 2001;345:433-42.

29. McAdam BF, Catella-Lawson F, Mardini IA, Kapoor S, Lawson JA, FitzGerald GA. Systemic biosynthesis of prostacyclin by cyclooxygenase (COX)-2: The human pharmacology of a selective inhibitor of COX-2. Proc Natl Acad Sci USA 1999;96:272-7.

30. Goodman S, Ma T, Trindade M, et al. COX-2 selective NSAID decreases bone ingrowth in vivo. J Orthop Res. 2002;20:1164-9.

31. Gajraj NM. The effect of cyclooxygenase-2 inhibitors on bone healing. Reg Anesth Pain Med 2003;28:456-65.

32. Rodgers A, Walker N, Schug S, et al. Reduction of postoperative mortality and morbidity with epidural or spinal anaesthesia: Results from overview of randomised trials. BMJ 2000;321:1493.

33. Ragucci MV, Leali A, Moroz A, Fetto J. Comprehensive deep venous thrombosis prevention strategy after total-knee arthroplasty. Am J Phys Med Rehabil 2003;82:164-8.

34. Jansen M, Fass J, Tittel A, et al. Influence of postoperative epidural analgesia with bupivacaine on intestinal motility, transit time, and anastomotic healing. World J Surg 2002;26:303-6.

35. Savage C, McQuitty C, Wang D, Zwischenberger JB. Postthoracotomy pain management. Chest Surg Clin N Am 2002;12:251-63.

36. Bach S, Noreng MF, Tjellden NU. Phantom limb pain in amputees during the first 12 months following limb amputation, after preoperative lumbar epidural blockade. Pain 1988;33:297-301.

37. Jahangiri M, Jayatunga AP, Bradley JW, Dark CH. Prevention of phantom pain after major lower limb amputation by epidural infusion of diamorphine, clonidine and bupivacaine. Ann R Coll Surg Engl 1994;76:324-6.

38. Katsuly-Liapis I, Georgakis P, Tierry C. Pre-emptive epidural analgesia reduces the incidence of phantom pain in lower limb amputees. Br J Anaesthesia 1996;76S:A401. (Abst)

39. Fisher A, Meller Y. Continuous postoperative regional analgesia by nerve sheath block for amputation surgery - A pilot study. Anesth Analg 1991;72:300-3.

40. Gan T, Sloan F, Dear GL, El Moalem HE, Lubarsky DA. How much are patients willing to pay to avoid postoperative nausea and vomiting? Anesth Analg 2001;92:393-400.

41. Alhashemi JA, Crosby ET, Grodecki W, Duffy PJ, Hull KA, Gallant C. Treatment of intrathecal morphine-induced pruritus following caesarean section. Can J Anaesth 1997;44:1060-5. 
42. Gan TJ. Postoperative nausea and vomiting - Can it be eliminated? JAMA 2002;287:1233-6.

43. VanDenKerkhof EG, Goldstein DH, Rimmer M, Tod D, Kwan Lee H. Handhelds versus paper for acute pain assessments: Time and content. Can J Anaesth 2002;49:21A. (Abst)

44. VanDenKerkhof EG, Goldstein DH, Lane J, Rimmer MJ, Van Dijk JP. Using a personal digital assistant enhances gathering of patient data on an acute pain management service: A pilot study. Can J Anaesth 2003;50:368-75.

45. Ko S, Goldstein DH, Van Den Kerkhof EG. Definitions of "respiratory depression" with intrathecal morphine postoperative analgesia: A review of the literature. Can J Anaesth 2003;50:679-88.

46. Wade JG. Patient safety in anesthesia - Continuing challenges and opportunities. Can J Anaesth 2003;50:319-22.

47. Vicente KJ, Kada-Bekhaled K, Hillel G, Cassano A, Orser BA. Programming errors contribute to death from patient-controlled analgesia: Case report and estimate of probability. Can J Anaesth 2003;50:328-32.
48. Bates T, Mercer JC, Harrison M. Symptomatic gall stone disease: Before and after cholecystectomy. Gut 1984;24:579.

49. Burkart BC, Bourne RB, Rorabeck CH, Kirk PG. Thigh pain in cementless total hip arthroplasty. A comparison of two systems at 2 years' follow-up. Orthop Clin North Am 1993;24:645-53.

50. Johnsson R, Thorngren KG. Function after total hip replacement for primary osteoarthritis. Int Orthop 1989;13:221-5.

51. Murray DW, Frost SJ. Pain in the assessment of total knee replacement. J Bone Joint Surg Br 1998;80:426-31.

52. Kroner K, Knudsen UB, Lundby L, Hvid H. Long-term phantom breast syndrome after mastectomy. Clin J Pain 1992;8:346-50.

53. Kroner K, Krebs B, Skov J, Jorgensen HS. Immediate and longterm phantom breast syndrome after mastectomy: Incidence, clinical characteristics and relationship to pre-mastectomy breast pain. Pain 1989;36:327-34.

54. Matsunaga M, Dan K, Manabe FY, Hara F, Shono S, Shirakusa T. Residual pain of 90 thoracotomy patients with malignancy and non-malignancy. Pain 1990;41(Suppl 1):S148. 


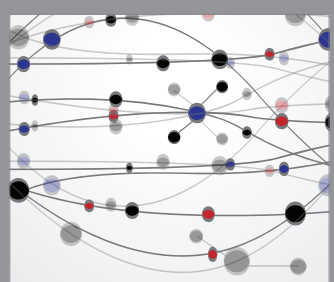

The Scientific World Journal
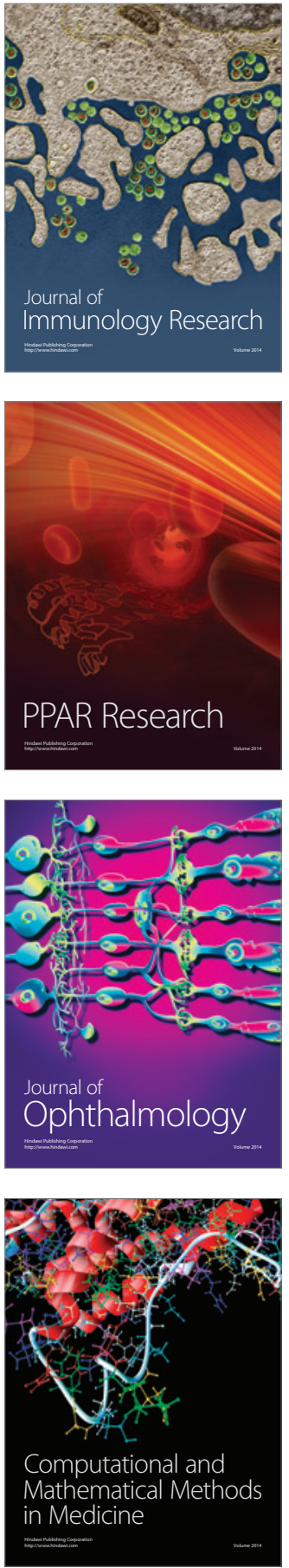

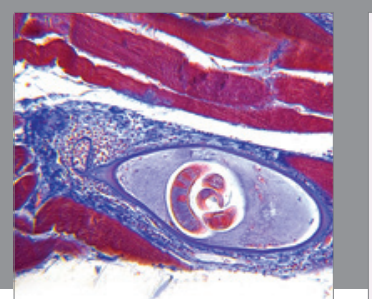

Gastroenterology Research and Practice

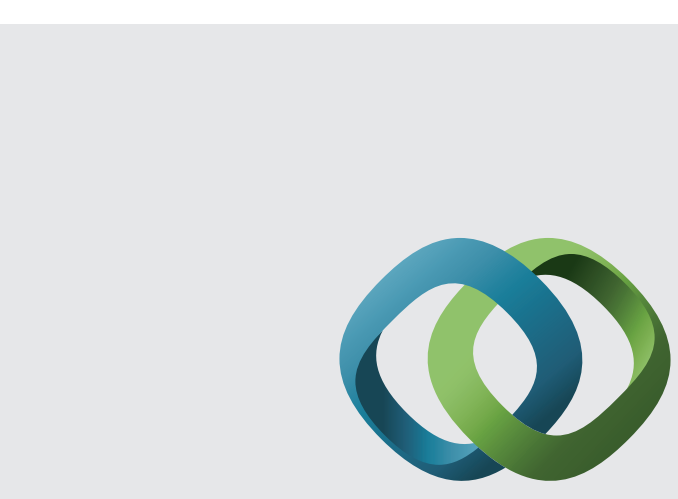

\section{Hindawi}

Submit your manuscripts at

http://www.hindawi.com
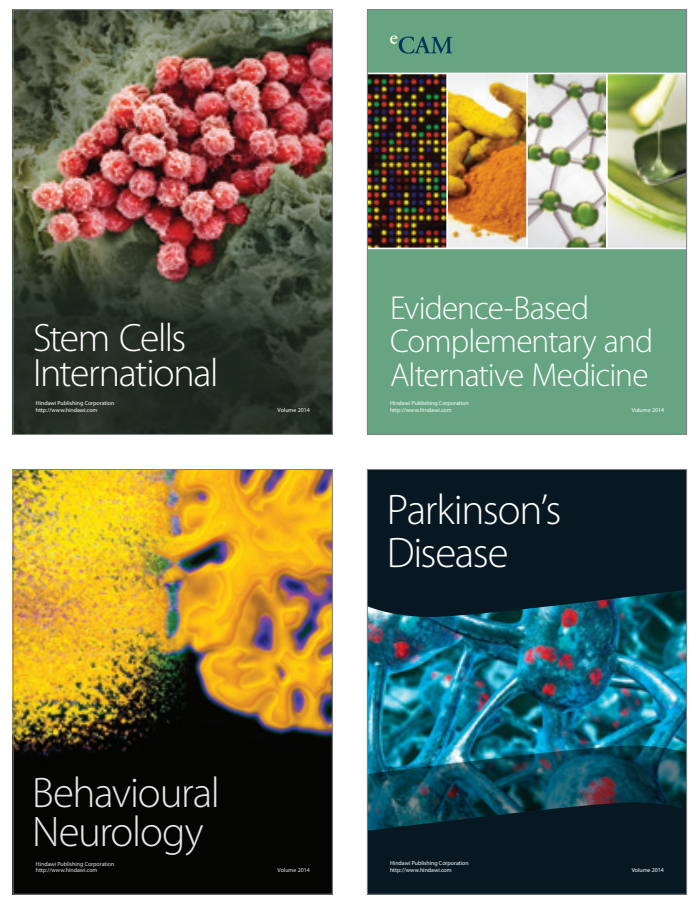
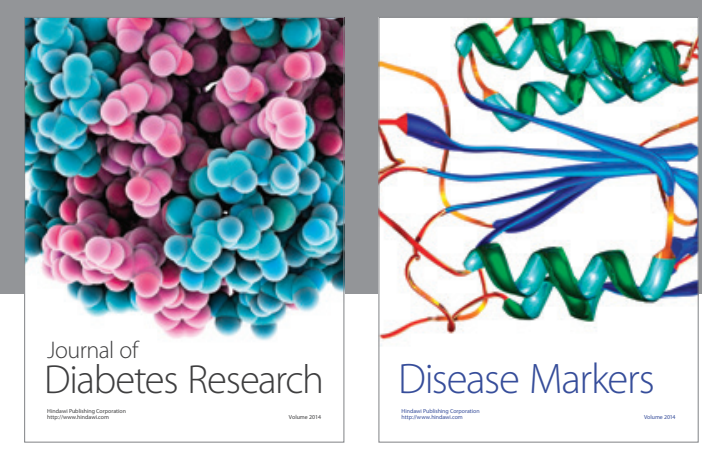

Disease Markers
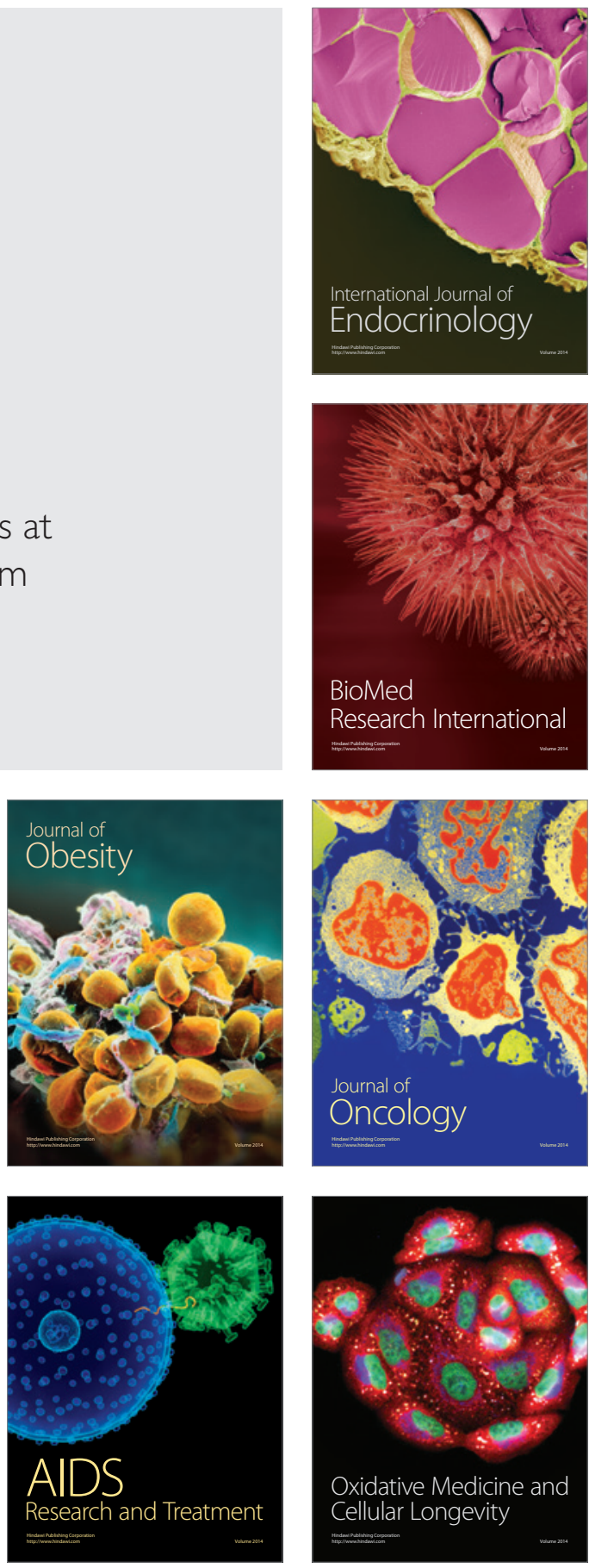